University of Nebraska - Lincoln

DigitalCommons@University of Nebraska - Lincoln

2010

\title{
Perceiver Effects as Projective Tests: What Your Perceptions of Others Say about You
}

\author{
Dustin Wood \\ Wake Forest University, dwood@wfu.edu \\ Peter D. Harms \\ University of Nebraska - Lincoln, pharms@gmail.com \\ Simine Vazire \\ Washington University in St Louis
}

Follow this and additional works at: https://digitalcommons.unl.edu/managementfacpub

Part of the Management Sciences and Quantitative Methods Commons

Wood, Dustin; Harms, Peter D.; and Vazire, Simine, "Perceiver Effects as Projective Tests: What Your Perceptions of Others Say about You" (2010). Management Department Faculty Publications. 78. https://digitalcommons.unl.edu/managementfacpub/78

This Article is brought to you for free and open access by the Management Department at DigitalCommons@University of Nebraska - Lincoln. It has been accepted for inclusion in Management Department Faculty Publications by an authorized administrator of DigitalCommons@University of Nebraska - Lincoln. 
Published in Journal of Personality and Social Psychology (2010) 99(1). Copyright 2010, American Psychological Association. Used by permission. DOI: 10.1037/a0019390. "This article may not exactly replicate the final version published in the Journal of Personality and Social Psychology. It is not the copy of record."

\title{
Perceiver Effects as Projective Tests: What Your Perceptions of Others Say about You
}

\author{
Dustin Wood, Department of Psychology, Wake Forest University, dwood@wfu.edu \\ Peter Harms, College of Business Administration, University of Nebraska-Lincoln, pharms2@unl.edu \\ Simine Vazire, Department of Psychology, Washington University in St. Louis
}

In three studies, we document various properties of perceiver effects - or how an individual generally tends to describe other people in a population. First, we document that perceiver effects have consistent relationships with dispositional characteristics of the perceiver, ranging from self-reported personality traits and academic performance to well-being and measures of personality disorders, to how liked the person is by peers. Second, we document that the covariation in perceiver effects among trait dimensions can be adequately captured by a single factor consisting of how positively others are seen across a wide range of traits (e.g., how nice, interesting, trustworthy, happy, and stable others are generally seen). Third, we estimate the one-year stability of perceiver effects and show that individual differences in the typical perception of others have a level of stability comparable to that of personality traits. The results provide compelling evidence that how individuals generally perceive others is a stable individual difference that reveals much about the perceiver's own personality.

Keywords: Person perception; Perceiver effect; Perceiver biases; Rating bias

We do not see the world as it is, we see the world as we are. - The Talmud

We are what we think. All that we are arises with our thoughts. With our thoughts, we make our world.

- The Buddha

Given that observer reports are usually collected to learn about the target rather than the person providing the rating, tendencies for raters to judge the same target differently are generally regarded as perceiver bias, or scale-use bias, and considered nuisance variance to be removed or minimized to the extent possible (Hoyt, 2000). However, we can also invert the usual use of observer reports and see what observer reports reveal about the raters. Indeed, numerous theorists have suggested that raters' perceptions of others are one of the most important determinants of their behavior (e.g., Beck, Freeman, \& Davis, 2004; Kelly, 1963; Laing, 1967; Mischel \& Shoda, 1995; Reis, 2008). Indeed, perceiver effects, which refers to general tendencies to perceive or judge others in particular ways (Kenny, 1994), can be thought to be a core component of a number of constructs commonly studied by psychologists. For instance, Machiavellianism is usually measured in part by asking individuals the extent to which they perceive a lack of sincerity, integrity, or selflessness in others' actions (Christie \& Geis, 1970), and narcissistic behavior is thought to be prompted in part by a belief that other people are inferior, uninteresting, and unworthy of attention (Beck

We would like to thank Andrew Beer and Alecia Santuzzi for their helpful comments on drafts of this article; Richard Gonzalez for helpful statistical advice relevant to analyses in the article; and Daniel Bureau, Shannon Stark, and Kristof Supinski for their invaluable help in the data collection for this project.

Manuscript received October 4, 2009; revision received January 27, 2010; accepted March 3, 2010. et al., 2004). Similarly, cognitive accounts of disagreeable or antisocial behavior suggest that these behavior patterns may originate in part from perceptual tendencies to more readily perceive others as hostile and threatening, which prepares individuals to respond aggressively (Dodge \& Crick, 1990; Raine, 2008). In short, many behavioral patterns commonly studied by psychologists are thought to be caused in part by how individuals perceive others in their environments, which in turn shapes the behavioral options that individuals see as desirable, adaptive, or appropriate (Campbell, Miller, Lubetsky, \& O'Connell, 1964). When considered in this way, individual differences in how raters tend to rate real targets on personality scales can be considered to be ecologically valid indicators of individuals' typical construal of others, which in turn is likely to be a major cause of their behavior. Despite this, there have been few or relatively limited examinations of how perceiver effects relate to other dispositional characteristics.

A limitation of previous studies linking personality to perceiver effects is that these investigations tended to assess perceptions of others only through statement-based instruments such as the Personality Belief Questionnaire (Beck et al., 2001) or through lab scenarios in which participants rated fictional targets (e.g., Lakey \& Cassady, 1990). Few studies have investigated how a broad range of personality and dispositional variables are associated with how individuals perceive real others in their social environments. Our goal in the present research is thus to conduct an in-depth investigation of the nature of perceiver effects. We focus on three major issues. First, we explore whether perceiver effects are associated with dispositional variables beyond "assumed similarity" effects (Cronbach, 1955). Second, we explore whether the major dimensions of individual differences in perceiver effects are comparable to the major dimensions of individual differences found in self-judgments (e.g., the Big Five). Third, we explore the stability of perceiver effects over the period of a year. We outline each of these goals in the following three sections. 
Beyond Assumed Similarity: The Dispositional Correlates of Perceptions of Others

One of the most common ways that investigators have attempted to understand the dispositional correlates of perceiver effects is to correlate participants' perceiver effect estimates with participants' own self-judgments on the same dimension (e.g., Kenny, 1994; Srivastava, Guglielmo, \& Beer, 2010). In other words, researchers have examined whether people tend to see others the same way they see themselves. These correlations are usually referred to as assumed similarity bias (Cronbach, 1955), although they have been referred to by numerous other names, including projection bias and the selfbased heuristic (Hoch, 1987; Ready, Clark, Watson, \& Westerhouse, 2000). The initial goal in measuring assumed similarity has been to examine its influence on accuracy in interpersonal perception, rather than as an interesting phenomenon in itself. As first noted by Cronbach (1955), an individual may achieve accuracy in judging a target's personality if (a) the target is actually similar to the rater and (b) the rater simply describes his or her own personality. If these conditions both exist, the individual can achieve accurate judgments without attending to any information about the target.

Despite the limited utility of this explanation for understanding the accuracy of personality judgments (due to the limited actual personality similarity of raters and targets in most circumstances), the frequent tendency to examine perceiver effects through the lens of assumed similarity seems to have led to a general tendency to report "convergent" correlations between perceiver effects and self-reported personality traits (e.g., do agreeable individuals also see others as agreeable?) but not "divergent" correlations (e.g., do agreeable individuals see others as more intelligent?). However, there are reasons to suspect that these divergent correlations exist. Early discussions of the perceiver effect considered the possibility of "complementary projection," whereby people act in ways that complement the way they tend to see others (e.g., acting dominant because they believe others are submissive; Campbell et al., 1964). Further, as noted by Beer and Watson (2008a), there are indications that individual differences in perceiver effects may have a simpler dimensionality than self-perceptions. Consistent with this, there are indications that women tend to rate others more positively than do men across all Big Five dimensions simultaneously (Winquist, Mohr, \& Kenny, 1998), which would be unlikely to occur if perceiver effects for all Big Five dimensions were orthogonal.

If perceiver effects have a simpler structure than the selfratings or single-peer judgments that were used to uncover the Big Five, we should not expect the relationships between self-ratings and other-perceptions to be trait-specific, as is implied by the assumed similarity hypothesis. For instance, there are indications that agreeable individuals describe others more positively on a range of traits beyond simply agreeableness; agreeableness has been related to lower levels of prejudice toward a wide range of groups (Graziano, Bruce, Sheese, \& Tobin, 2007) and to both the perceived agreeableness and extraversion of others (Graziano \& Tobin, 2002; other Big Five traits were not measured). We suspect that there are many divergent or nonparallel relationships that may exist between self-ratings and perceiver effects (e.g., self-rated extraversion and perceived agreeableness of others), many of which may match or even exceed the magnitude of assumed similarity correlations.

Many normal and abnormal personality traits are thought to be characterized by systematic biases in the perception of others, and these do not always reflect assumed similarity relationships. For instance, although narcissists may perceive others as being uninteresting or worthless, this may not reflect how they see themselves (American Psychiatric Association, 1994). Similarly, individuals displaying behaviors typical of paranoid personality disorder may believe that others are malevolent and untrustworthy, even though they may not see themselves that way (American Psychiatric Association, 1994). In addition to exploring divergent correlations between perceiver effects and self-perceptions of the Big Five, we thus also cast a wider net to investigate the relationships between perceiver effects and dispositional variables beyond the Big Five. Given the importance of individual differences in the perception of others in some theories of personality disorders (Beck et al., 2004), we explore the relationships between perceiver effects and measures of personality disorders. We also explore the relationship between perceiver effects and measures of well-being and of the quality of social relationships.

\section{Major Dimensions of Perceiver Effects}

Most of the research on how individuals tend to rate others has implicitly assumed that the structure of perceiver effects does not differ much from the structure of self-judgments. That is to say, if the Big Five is regarded as an adequate structure of the major dimensions of self-reports or single-peer ratings, then it is assumed to also be an adequate structure for perceiver effects. However, as detailed by Kenny (1994), single-personality judgments - whether of oneself or of another person-can be viewed as the composite of three major effects: (a) how the rater tends to rate others in the population in general (perceiver effects), (b) how the target tends to be rated by others in the population in general (target effects), and (c) how the rater tends to uniquely judge particular targets in ways that cannot be accounted for by these other effects (relationship effects; in self-judgments this is how the rater uniquely views him- or herself), where population here refers to the people who can rate others or be rated by others. Although the Big Five and similar taxonomies might adequately describe the major dimensions of the combination of these three effects that emerges in self and other ratings, they may not capture the major dimensions of each effect considered separately.

Little research has investigated the dimensionality of perceiver effects. There are reasons to think that the structure of perceiver effects can be adequately described by fewer factors than self-reported personality traits. This may happen because perceiver effects can be thought of as individual differences in how people perceive the same "generalized other." That is, we can think of the comparison of how different individuals rate many targets on average as indicating how the individuals differ in describing the same "average person" in the population they are rating. Some research has suggested that when all raters are judging the same target (e.g., a particular political candidate) instead of different targets (e.g., rating themselves, a friend, or a spouse), the factor structure of trait ratings may become simpler and less differ- 
entiated (Caprara, Barbaranelli, Fraley, \& Vecchione, 2007). This may happen in part because individual differences in ratings in such a situation are no longer influenced by differences in the target being rated. This reasoning, and the likelihood that many individual difference characteristics (such as gender and agreeableness) correlate with perceiver estimates of multiple traits simultaneously, lead us to suspect that there may be fewer major dimensions in the general perception of others than in self-perceptions. Similarly, a recent investigation by Srivastava and colleagues (2010) found that although covariation between perceiver effect estimates created by averaging scores a rater provided of different targets could be adequately explained by the five-factor structure generally found in self-ratings or ratings from knowledgeable informants (Goldberg, 1993), the model fitted better when these factors were allowed to covary through a common factor of overall positive evaluation (i.e., whether others were seen as generally having positive vs. negative qualities). Accordingly, we attempt to identify the number of factors necessary to explain the dimensionality of perceiver effects through the use of factor analysis.

\section{Stability of the Perceptions of Others}

Another topic that has received little attention in the literature concerns the stability of individual differences in perceiver effects over time. Malloy, Sugarman, Montvilo, and Ben-Zeev (1995) reported low levels of one-year stability in perceiver effect estimates among elementary-school-aged children $(r s \approx 0.20)$, whereas target effects showed higher stabilities over the same intervals. Similarly, Srivastava and colleagues (2010) found stabilities of perceiver effect estimates to be approximately 0.50 over the period of a week. However, the small amount of research on the topic leaves the stability of perceiver effects an open question.

The stability of an individual's tendency to see people in certain ways is important for understanding the extent to which an individual's general perceptions of others are "traitlike." Further, many theorists are interested in perceptual tendencies as causal variables, noting that individuals' perceptions of their environment are a proximal source of their behavior, in that people often act on how they perceive their environments even when their perceptions do not reflect the objective environment (Beck et al., 2004; Kelly, 1963; Reis, 2008). Consequently, if individual differences in the general perceptions of others are relatively stable over time, this should increase individuals' ability to direct and maintain their patterns of behavior over time, as the consistency of an environment serves to increase the potential for the environment to direct lasting dispositional change (e.g., Caspi, Herbener, \& Ozer, 1992; Roberts, Wood, \& Caspi, 2008). Consequently, empirically estimating the stability of perceiver effects should provide a better idea of the extent to which perceiver dimensions reflect stable ways people construe their interpersonal environments.

We address these questions in three studies. First, we explore how perceiver effects of Big Five traits are related to self-reported personality traits and other dispositional variables (Studies 1, 2, and 3). Then, using data sets with a broader range of peer-rated trait adjectives, we conduct analyses in which we explore the major dimensions of covariation among perceiver effects (Studies 2 and 3). Finally, we explore the stability of perceiver effects over a year (Study 3). We conclude the article with a discussion of perceiver effects as individual difference variables.

\section{Study 1: Beyond Assumed Similarity}

Our first goal was to explore how variation in perceptions of others is associated with the perceiver's own personality traits. The relationships between how individuals judge others and how they judge themselves have been investigated several times; however, this is most frequently done to document "assumed similarity" (e.g., does perceiving oneself as extraverted correlate with perceiving others as extraverted?). These studies have tended to show that people judge others in a similar manner to how they judge themselves, although the strength of assumed similarity effects varies by trait. Within the Big Five framework, the strongest effects are generally observed for agreeableness, and the weakest for extraversion (e.g., Beer \& Watson, 2008b; Kenny, 1994). Given that researchers often limit their analysis to convergent correlations between self-perceptions and perceiver effects (i.e., assumed similarity correlations), we examine the divergent correlations, which explore whether perceptions of others correlate not just with self-judgments of the same trait but with self-judgments of different traits. Documenting divergent correlations between how individuals see themselves and how they see others would clearly indicate that there is more to the perceiver effects than simply the projection of one's own self-image onto others.

\section{Method}

Participants. A total of 165 undergraduate students (100 female) from a large state university in Texas participated in exchange for either course credit or a cash reward (\$10 and a 1 in 10 chance to win $\$ 100$ more). Participants were asked to sign up in groups of five friends who were all previously acquainted. Some groups included dyads that had not met before, but $97 \%$ of the dyads were previously acquainted. On average, participants had known their group members for over three years $(M=3.12, S D=4.29)$. The students ranged in age from 18 to 22 years $(M=18.8, S D=1.7)$. According to self-reported ethnicity, 70 participants were Asian or Pacific Islander, 65 were Caucasian, 19 were Hispanic, 9 were African American, one was of mixed ethnicity, and one did not provide an ethnicity. ${ }^{1}$

Procedure and materials. Participants were recruited by posting flyers in dorms, making announcements in introductory psychology classes, and handing out candy and flyers at busy campus intersections. Participants signed up by visiting a website and completing a form, which required five names of previously acquainted friends who were all undergraduate students and at least 18 years of age. No details about the purpose of the study were given in the advertisements or on the website. Participants signed up their group for a specific 3-hr session. All sessions were held on Saturday and Sunday afternoons. After signing up, participants received an e-mail with directions to the laboratory.

\footnotetext{
${ }^{1}$ Other data from this sample have been used in Vazire (2010) and Back et al. (in press). The analyses from these other investigations do not overlap with the current analyses.
} 
Upon arriving at the laboratory, each "friend group" was shown to a room where an experimenter described the study and administered the consent forms. Participants then completed a battery of measures including round-robin ratings of their group members, including themselves. Group members were seated together at a table, but folders were put up so that they could not see each other's ratings.

Participants rated each group member on a 40-item inventory. The first 10 items consisted of the Ten Item Personality Inventory (Gosling, Rentfrow, \& Swann, 2003), which in past research has shown high convergent validity with other widely used Big Five inventories in self- and observer-reports and has had very good test-retest reliability (mean $r$ $=0.72$ over 6 weeks; Gosling et al., 2003). Participants rated each group member on the same 15-point Likert-type scale, ranging from 1 (Not at all) to 15 (Extremely). Participants wrote the letter corresponding to the group member they were rating above the number they chose for that person and were told not to use the same number twice on a single scale (i.e., participants had to give each group member different scores from each other on a given item). The remaining 30 items were unrelated to the analyses conducted here.

Participants also completed a number of other measures (see Vazire, 2006, 2010, for a full description). Of relevance to the present analyses, participants completed the Beck Depression Inventory (BDI; Beck, Rial, \& Rickels, 1974; an item dealing with suicidality was omitted for ethical reasons; $\alpha=$ 0.68), the 16-item version of the Narcissistic Personality Inventory (NPI; Ames, Rose, \& Anderson, 2006; $\alpha=0.70)$, and the Wonderlic IQ test (Wonderlic, 1983). College GPA and SAT scores were also obtained from the registrar two years after the rating data were collected.

\section{Analyses}

Modeling relationships between perceiver characteristics and perceiver effects. In the results that we report for this and the later studies, we report the correlations linking a perceiver's dispositional characteristics (e.g., a rater's gender, GPA, self-rated extraversion) to how the perceiver sees a single other target on some dimension (e.g., extraversion). These correlations can be interpreted as measuring how personality differences among perceivers on dimension $X$ relate to how the perceivers judge a single target on dimension $Y$. Consequently, the correlations we report are somewhat smaller than if multiple ratings by the individual perceivers were aggregated. To estimate how dispositional characteristics are associated with how individuals perceive others in the population in general, we estimated a second correlation by dividing this correlation by the square root of the intraclass correlation (ICC) associated with the perceiver effect (Malloy et al., 1995), which we report in all studies. Note also that estimating this second correlation is equivalent to a partial correction for unreliability (i.e., the unreliable expression of perceiver effects in a perceiver's judgment of a single target); it does not correct for unreliability on the side of the dispositional variable, such as self-reported extraversion.

Modeling relations between perceiver dimensions. Perhaps the most intuitive way to measure the relation between perceiver effects for different traits is to average trait ratings that a rater has collected across targets and correlate these averages together. However, this method for estimating relations be- tween perceiver effects of different traits will result in a matrix in which different traits are linked not just through perceiver effects but also through target effects and relationship effects due to the fact that characteristics of the same targets being rated represent a significant percentage of the variance in the perceiver effect estimates that are created in this manner, especially when the number of ratings being averaged is relatively small. To investigate how perceiver effects for different traits are related to one another, we thus created a correlation matrix consisting solely of correlations relating judgments a rater made of one target to judgments the same rater had made of a different target (i.e., how do a rater's impressions of target $i$ correlate with the rater's impressions of a different target $i^{\prime}$ ?). If raters are randomly assigned to targets, the only characteristics linking a rater's judgments of two different targets are tendencies for raters to judge targets in the sample in particular ways (i.e., perceiver effects). Consequently, this perceiver-effect matrix can be used to examine how perceiver judgments are related to one another along both same and different dimensions simultaneously (e.g., if a judge rates one target as extraverted, how likely is the same judge to rate a different target as extraverted? or agreeable?). This matrix was formed by creating all combinations of a rater's judgments of two different targets and using the double-entry method described by Gonzalez and Griffin (2000; Griffin \& Gonzalez, 1995) to make the correlations invariant against the arbitrary assignment of the ratings into columns when estimating the correlations.

The diagonals of the matrix give the ICCs of trait perceiver effects, which detail the extent to which ratings that an individual provides of different individuals on the same trait correlate with one another. We refer to the off-diagonals as the "cross-class" correlations of perceiver effects, which detail the extent that ratings a rater has made of one target correlate with different trait ratings the rater has made of a different target (e.g., how much do an individual's ratings of one target's extraversion correlate with the individual's ratings of a different target's agreeableness?). To our knowledge, this is the first time cross-class correlations have been reported. These can be used to understand the dimensionality of perceiver effects. The cross-class correlations should be approximately zero if the perceiver effects for Big Five traits are independent of one another, and at the other extreme they should be approximately the same size as the ICCs if the perceiver effects of different Big Five traits are expressions of a single perceiver dimension.

\section{Results and Discussion}

Intraclass and cross-class correlations of perceiver effects. Using the perceiver-effect matrix described previously, we were able to estimate the extent to which a rater's perceptions of one target were associated with the rater's perceptions of a different target; these are shown in the left half of the top section of Table 1. The magnitude of the ICCs of perceiver effects differed substantially across the Big Five. The greatest ICCs were found for openness $(r=0.18)$, emotional stability $(r$ $=0.16)$, and agreeableness $(r=0.13)$. Substantially lower estimates were found for conscientiousness $(r=0.04)$ and extraversion $(r=-0.03)$. The results suggest that there were moderate individual differences in how people tended to perceive targets on agreeableness, emotional stability, and openness 
Table 1

Relationships Between Ratings of Others and Self-Ratings for Big Five Characteristics

$\underline{r \text { between ratings of two different targets }}$

Perceiver effect dimension
Study 1: Ratings of friends
1. Extraversion
2. Agreeableness
3. Conscientiousness
4. Emotional stability
5. Openness to experience

Study 2: Ratings of dormitory floormates

1. Extraversion $\quad 0.29$

2. Agreeableness $\quad 0.17$

3. Conscientiousness $\quad 0.21$

4. Emotional stability $\quad 0.20$

5. Openness to experience
2

$-0.03$

0.04

0.05

$0.00 \quad 0.16$

$0.00 \quad 0.08$
3

0.04
0.05

0.05

0.09
4

0.16
0.07

0.21

0.20

0.22

0.15
0.24

0.22

0.18

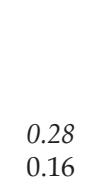

0.16
5

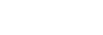

Study 3: Ratings of organization members

1. Extraversion $\quad 0.15$

2. Agreeableness $\quad 0.20$

3. Conscientiousness $\quad 0.20$

4. Emotional stability $\quad 0.11$

5. Openness to experience
0.27

0.16

0.12

0.27
0.15

0.05

0.20

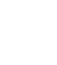

$r$ between ratings of a target (rows) and self-ratings (columns)

\begin{tabular}{lllll}
\multicolumn{5}{c}{ self-ratings (columns) } \\
\hline & 2 & 3 & 4 & 5 \\
\hline & & & & \\
-0.04 & 0.07 & $\mathbf{0 . 0 8}^{*}$ & 0.03 & 0.03 \\
-0.01 & $\mathbf{0 . 1 9 ^ { * }}$ & -0.01 & $0.14^{*}$ & 0.00 \\
$0.09^{*}$ & $\mathbf{0 . 1 0}^{*}$ & $0.09^{*}$ & 0.07 & 0.03 \\
0.03 & $0.13^{*}$ & 0.02 & $\mathbf{0 . 1 4 ^ { * }}$ & 0.02 \\
-0.01 & $0.12^{*}$ & 0.06 & -0.05 & $\mathbf{0 . 1 6 ^ { * }}$
\end{tabular}

Note. Study 1: $N=649$ total ratings from 165 raters; Study 2: $N=1,004$ total ratings from 364 raters; Study 3: $N=802$ total ratings from 311 raters. Correlations are between perceptions of others' Big Five traits (in the rows and first set of columns) and self-rated Big Five traits (in the second set of columns). The type of rating used to capture perceptions of others and the number of ratings used to estimate the correlations are given separately for each study. The same-trait perceiver effects and the assumed similarity correlations are shown in italics. The highest correlation between how the participant rated targets and a self-rated personality trait is in bold for each row.

${ }^{*} p<0.05$.

but negligible individual differences in how people perceived targets on conscientiousness and extraversion. ${ }^{2}$

The cross-class correlations were not particularly large in the current study; however, they nonetheless appeared to be relatively large in relation to the size of the ICCs. The ICCs for Big Five perceiver effects averaged 0.10. The cross-class correlations in the matrix averaged 0.06 , indicating that they were roughly $60 \%$ of the size of the same-trait correlations. Indeed, individuals who rated one individual as agreeable were likely to rate a different individual as emotionally stable and vice versa $(r=0.16)$; this cross-class correlation was equal in magnitude to the size of either trait's ICC, indicating that the perceiver effects for these traits should be highly associated with one another.

Relation between ratings of others and dispositional characteristics. We next correlated scores that the participants gave to single targets on the Big Five with the participants' own scores on the Big Five. To estimate the relationship between dispositional variables and ratings of others in this and the remaining studies, we correlated participants' scores on dispositional variables to the ratings participants provided for targets they rated. Again, the correlations we show relate a rater's dispositional variables to how the rater perceives a single target. Because multiple target ratings are nested within raters, statistical significance values for these correlations were obtained through linear mixed modeling. These correlations are shown on the right side of the top section of Table 1. Correlations on the diagonal of the correlation matrix represent the traditional assumed similarity correlations (i.e., the correlation between how participants see themselves and how they see someone else on the same trait). The highest correlation for each row is shown in bold to indicate which self-rated Big Five dimension has the highest association with a given perceiver dimension.

Relations between perceiver effects and self-rated personality traits. As can be seen in Table 1, four of the Big Five personality traits showed significant assumed similarity correlations. The largest effect was found for agreeableness $(r=$ $0.19)$, followed by openness $(r=0.16)$, emotional stability $(r$ $=0.14)$, and conscientiousness $(r=0.09$, all $p$ s $<0.05)$. Only extraversion failed to show an assumed similarity effect $(r=$ -0.04). Following past research, this indicates that individuals are more likely than chance to describe others as they see themselves.

\footnotetext{
2 The variance of perceiver effects is estimated more commonly through linear mixed models as the ICC associated with raters. When done this way, the variances were estimated at 0.00 for extraversion, 0.14 for agreeableness, 0.04 for conscientiousness, 0.17 for emotional stability, and 0.18 for openness, which indicates that the two methods provide similar answers. It should be noted that negative ICCs are not expected to occur when raters rate a large number of people; they should only occur when raters are actively contrasting their ratings from their previous ratings and/or when raters have rated few targets (Kenny, Mannetti, Pierro, Livi, \& Kashy, 2002). Because participants were told they could not give the same value twice for different targets, this should have generally decreased ICCs and could have produced the contrast conditions necessary for negative ICCs.
} 
Of more interest were the correlations on the off-diagonals of the correlation matrix. We found numerous correlations between self-perceptions and perceptions of others for non-matching traits. Self-ratings of agreeableness were associated with perceiving others as significantly more conscientious, emotionally stable, and open (all $r s \geq 0.10$ ). Interestingly, these relationships between perceptions of others and selfrated agreeableness were all nearly equal in magnitude to the magnitude of the assumed similarity effects for each trait. Additionally, self-ratings of emotional stability were associated with perceiving others as agreeable $(r=0.14)$, and self-ratings of conscientiousness were associated with perceiving others as extraverted $(r=0.08)$. Finally, self-ratings of extraversion were associated with perceiving others as conscientious $(r=0.09)$ despite the fact that extraversion did not show an assumed similarity correlation. The regular observation of off-diagonal effects clearly indicates that perceiver effects reflect more than simply projections of one's own self-image onto other people.

Relations between perceiver effects and other dispositional characteristics. We also examined how perceiver effects were associated with a range of other characteristics assessed in this sample. These correlations are shown in Table 2.

First, we found that gender was associated with perceiver effects, with women tending to judge others as significantly more extraverted, conscientious, and open to experience than did men (all rs between 0.09 and 0.18). A rater's level of depression, based on the rater's BDI score, was also associated with a range of perceptions of others, with depressed raters tending to judge others as significantly more extraverted $(r=0.08)$, less agreeable $(r=-0.09)$, and less emotionally stable $(r=-0.12)$. Narcissism scores from the NPI were associated with negative perceptions across every dimension of personality, with higher narcissism being associated with judging others as less extraverted, agreeable, conscientious, emotionally stable, and open to experience (all $r \mathrm{~s} \leq-0.11$, ps $<0.05)$. Finally, the measures of intellectual ability showed some association with perceptions of others. Higher GPA, SAT, and IQ scores were all associated with tendencies to perceive others as less open to experience (all $r \mathrm{~s} \leq-0.08, p \mathrm{~s}<$ 0.05). In addition, higher GPA was associated with a small tendency to rate others as higher in agreeableness $(r=0.08)$, and higher SAT scores were associated with a small tendency to rate others as lower in conscientiousness $(r=-0.09)$.

Study 2: Structure and Correlates of Perceiver Effects

The nonparallel relationships between dispositional characteristics and perceiver effects suggested there was more to perceiver effects than simple assumed similarity biases. People high in agreeableness were significantly more likely to rate targets as having positive levels of almost all Big Five dimensions, whereas narcissism was associated with more negative views of others along all Big Five dimensions. Furthermore, tendencies to perceive others as extraverted were not associated with the perceiver's self-rated extraversion but were associated with the perceiver's gender and level of depression and narcissism.

Despite the promising nature of the first study, it had several important limitations. Our analyses of the perceiver-effect matrix provided some indication that the perceiver effects for different traits may be associated with one another. However, the magnitude of both intraclass and cross-class per- ceiver effects were almost certainly artificially lowered due to the fact that the procedure forced raters to give each target a different rating. Because perceiver effects are by definition differences in how individuals generally rate others in a population, forcing people to vary their ratings more than they normally should result in an underestimation of the extent to which perceiver effects infuse ratings. Additionally, groups in this study were made up of people who were generally friends with one another. Because participants formed their own groups, a perceiver's judgments could reflect not just perceiver effects but also affiliative preferences (e.g., tendencies to rate others in the group as extraverted could be due to tendencies to select extraverted friends). Consequently we continued by studying a different context, in which participants were less likely to rate friends and were free to give multiple targets the same rating.

Despite these limitations of Study 1, the finding that characteristics such as agreeableness, depression, and narcissism were correlated with perceptions of others along many or all Big Five dimensions simultaneously was consistent with our expectation that perceiver effects have correlates beyond assumed similarity and may have a simpler structure than selfratings. In Study 2, we explored these questions more directly.

\section{Method}

Participants. A total of 643 students were invited to participate in a study called the Personality and Social Relationship Study, which was described as investigating the relationships students had with their peers within the dormitory system at Wake Forest University. Participants completed the study online and were given $\$ 15$ after completing the study, which involved rating their own personality characteristics and those of three randomly selected members of their floor as described further later in this paragraph. A total of 365 individuals completed the measures used in the present investigation. Of these participants, 219 were female (60\%). A total of 1,004 usable ratings were collected from these participants; ratings were excluded if they contained missing values or if the person did not vary the ratings. The study was conducted among residents of freshman dormitories near the end of their second semester of school, after they had been living on their floor for approximately seven months. University housing administrators reported that freshmen had been randomly assigned to their dormitories and roommates, with the only constraint that they had been assigned to same-sex floors.

Table 2

Correlations Between Participant Characteristics and Perceiver Effects (Study 1)

\begin{tabular}{lcccccc}
\hline $\begin{array}{l}\text { Participant } \\
\text { characteristic }\end{array}$ & E & & P & C & S & O \\
Gender $(0=\mathrm{M}, 1=\mathrm{F})$ & $0.17^{*}$ & 0.05 & $0.09^{*}$ & -0.04 & $0.18^{*}$ \\
Depression (BDI) & $0.08^{*}$ & $-0.09^{*}$ & -0.02 & $-0.12^{*}$ & 0.05 \\
Narcissism (NPI) & $-0.14^{*}$ & $-0.11^{*}$ & $-0.12^{*}$ & $-0.11^{*}$ & $-0.14^{*}$ \\
GPA & -0.01 & $0.08^{*}$ & -0.04 & 0.04 & $-0.09^{*}$ \\
SAT & -0.07 & -0.03 & $-0.09^{*}$ & -0.02 & $0.11^{*}$ \\
IQ (Wonderlic) & -0.03 & 0.01 & -0.04 & 0.00 & $-0.08^{*}$
\end{tabular}

Note. All correlations are based on 602 or more ratings from 152 or more different raters. $\mathrm{E}=$ extraversion; $\mathrm{A}$ = agreeableness; $\mathrm{C}=$ conscientiousness; $\mathrm{S}=$ emotional stability $; \mathrm{O}=$ openness; $\mathrm{BDI}=$ Beck Depression Inventory; NPI = Narcissistic Personality Inventory; Wonderlic $=$ Wonderlic IQ test.

${ }^{*} p<0.05$. 
Materials and Procedure

Inventory of individual differences in the lexicon. In order to obtain a broad survey of participant characteristics, we asked participants to complete an early 57-item version of the Inventory of Individual Differences in the Lexicon (IIDL; Wood, Nye, \& Saucier, 2009). The IIDL is designed to measure a broad array of distinguishable individual differences that can be identified within the lexicon through the use of a single item consisting of a pair of synonymous trait adjectives (e.g., bold/assertive, outgoing/sociable, enthusiastic/excited). ${ }^{3}$ Participants completed the inventory to describe themselves, using the instructions "How do you see yourself in general?" and given the stem "I see myself as someone who is ..." Four items of the IIDL pertaining more to demographic or nonbehavioral characteristics (i.e., items concerning perceptions of a target's height, health, wealth, and age) were excluded. Participants first rated their own personality on the IIDL, and then at the end of the survey they rated up to three different residents of their floor on the IIDL. In order to increase the likelihood that participants would be assigned to rate people they knew, we asked participants to rate randomly selected targets who lived within a couple doors of their own room.

Analyses in a sample that contained both the Big Five Inventory (John \& Srivastava, 1999) and IIDL reported by Wood and colleagues (2009) suggested that Big Five marker scales could be created by averaging selected IIDL items. An extraversion scale was made from items outgoing/extraverted, enthusiastic/excited, loud/noisy, and bashful/shy (reverse-scored [RS]); in self-ratings the internal consistency was $a=0.65$. An agreeableness scale was made from the items kind-hearted/caring, supportive/encouraging, unsympathetic/unfriendly (RS), and angry/hostile (RS); $\alpha=0.73$. A conscientiousness scale was made from the items organized/efficient, dependable/ reliable, messy/sloppy (RS), and unreliable/undependable (RS); a $=0.72$. An emotional stability scale was made from the items insecure/unsure (RS), tense/nervous (RS), sad/unhappy (RS) and calm/relaxed; $\alpha=0.70$. And an openness scale was made from the items creative/artistic, complex/deep, intelligent/smart and narrow-minded/close-minded (RS); $\alpha=0.43$.

Personality disorder scales. To investigate how perceiver effects might be associated with personality disorders, we had participants complete selected subscales from the Millon Clinical Multiaxial Inventory-III (MCMI-III; Millon, 1997). We selected subscales that we suspected would be most related to individual differences in perceiver effects as assessed here, and we included at least one disorder from each of the three major clusters of personality disorders (American Psychiatric Association, 1994). We chose to include the subscales assessing narcissistic, paranoid, antisocial, avoidant, borderline, and obsessive- compulsive personality disorders. The scales were measured using standard scoring for the MCMIIII scales, with the exception that items pertaining to drug use or suicidality were eliminated to alleviate participant concerns about confidentiality. This resulted in the elimination of five of the 79 total items.

Life satisfaction. Life satisfaction was measured using a shortened three-item version of the Satisfaction with Life Scale (Pavot \& Diener, 1993). The items were "In most ways my life is close to my ideal," "The conditions of my life are excellent," and "I am satisfied with my life" ( $\alpha=0.87)$.
General liking by others. Participants in the study rated the extent to which they liked every other individual living on their dorm floor, using a 7-point scale ranging from 1 (strongly dislike) to 7 (strongly like). The average agreement between two different liking judgments of the same target (the liking ICC) was estimated as $r=0.32$. Liking ratings were aggregated across anyone who rated the participant to form an estimate of the extent to which the individual was generally liked by others. Given that the average number of raters per target was 12.9 (range: 3-22), the expected reliability of the average liking estimates using the Spearman-Brown prophecy formula was estimated at 0.86 .

\section{Results}

Assumed similarity. We first examined the assumed similarity correlations for Big Five traits. As shown in the right half of the middle section of Table 1, there were significant assumed similarity effects for all Big Five traits except extraversion. However, in this study, the best predictor of a perceiver effect for any Big Five dimension was invariably selfreports of agreeableness. This again pointed to the limitations of assumed similarity as an explanation of the sources of perceiver effects for different traits.

Intraclass and cross-class correlations of trait perceiver effects. We examined the extent to which a rater's judgments of a target's traits were associated with the same rater's judgments of a different target's traits. As can be seen in the left side of the middle section of Table 1 , the cross-class correlations differed substantially from zero, indicating that perceiver effects for the Big Five were not independent of one another. In fact, the average cross-class correlation of the perceiver effects for Big Five traits was 0.19, versus an average ICC of .25, indicating that cross-trait correlations were on average $75 \%$ of the size of same-trait correlations. This provides clear indication that the perceiver effects for Big Five traits are far from orthogonal from one another. ${ }^{4}$ Structure of perceiver effects within the IIDL. We next examined the structure of perceiver effects by conducting a factor analysis on the perceiver-effect correlation matrix for all 57 IIDL items. Principal axis factoring was used to extract factors, and the first 10 eigenvalues were $7.6,2.7,1.4,1.2,1.2,1.1,1.1,1.1,1.0$, and 1.0. Examination of the scree plot showed little reason to extract more than two factors. This was supported by examining the three-factor solution, which revealed no items on the third factor with loadings above 0.25 . Consequently, we describe the features of the one- and two-factor solutions.

\footnotetext{
${ }^{3}$ The IIDL items are discussed in the text by italicizing the adjectives and separating them by a slash mark (e.g., outgoing/sociable) despite the fact that participants are presented with the same items in a slightly different format (i.e., "outgoing, sociable"). This convention was adopted to avoid a confusing proliferation of commas and quotation marks in the text.

${ }^{4}$ It is possible that the high intercorrelations among perceiver effects for Big Five traits may be a property of the IIDL estimates of the Big Five rather than of perceiver effects and thus would be observed in self-reports. This did not appear to be the case. To examine this, we correlated self-ratings of Big Five traits with self-ratings on the same scales collected approximately four days later. The size of off-diagonal correlations (e.g., self-ratings of extraversion with self-ratings of agreeableness four days later) was only $26 \%$ of the magnitude of ondiagonal correlations (e.g., self-ratings of extraversion with self-ratings of extraversion four days later).
} 
The loadings of IIDL items on the first unrotated factor is shown in Table 3. The factor contrasted positive and negative perceptions of others, with the highest loading items of the dimension indicating that the dimension concerned individual differences in the extent to which individuals tended to rate others as having a host of positive characteristics, ranging from being interesting, impressive, trustworthy, and friendly to being happy and emotionally stable.

When two factors were extracted and rotated using principal axis factoring and varimax rotation, the positive and negative poles of the dimension identified in the one-factor solution split into separate factors. The highest loading items of the first factor consisted of the items great/wonderful, accomplished/successful, skilled/talented, affectionate/passionate, extraordinary/exceptional, kind-hearted/caring, happy/joyful, and cheerful/good-humored (all factor loadings were between 0.53 and 0.42 ), which indicates that the factor represents variation in perceptions of the dynamism, status, or agentic tendencies of others. The highest loading items for the second dimension consisted of the adjective pairs unstable/disturbed, ashamed/guilt-prone, unsympathetic/unfriendly, cruel/abusive, bad/immoral, tense/nervous, angry/hostile, and sad/unhappy (all loadings were between 0.47 and 0.38 ), which indicates that the factor represents variation in how antisocial and neurotic others are typically perceived.

Additional analyses suggested that the separate positive and negative perceptions of others found in the two-factor solution may not differ from each other importantly. Analysis of these two dimensions suggested that when factor scoring was not forced on these dimensions, they showed substantial negative correlations with one another. In particular, the cross-trait perceiver effect (how much rating a target as antisocial is associated with rating a different target as interesting) was over half the size of the same-trait perceiver effect for these dimensions, suggesting that the latent correlation between these two dimensions was greater than -0.50 . Additionally, the correlates of the two scales were largely mirrors of one another, with the dispositional characteristics that were correlated with positive perceptions being correlated in the opposite direction and at roughly the same magnitude with the second dimension (the column-vector correlation of the two dimensions across the characteristics shown in Table 3 was -0.92).

Given the redundancy of the pattern of relationships with dispositional variables for the two factors, we considered only the properties concerning the first unrotated factor in the analyses that follow. To do this, we created a perceiver score by averaging the 10 positive items with the strongest loadings and the 10 negative items with the strongest loadings after reverse-scoring to create a 20 -item measure; we refer to this dimension as the perceived positivity of others. We estimated the perceiver ICC for the positivity dimension to be 0.38 , indicating that there were fairly large individual differences in how positively raters judged targets in the group in general and that these ratings have a fairly large impact on single-observer reports.

Relationships between perceived positivity of others and dispositional characteristics. We next examined how the perceived positivity of others was associated with other dispositional variables. As in Study 1, the correlations that are reported show how dispositional variables are associated with perceptions of a single target of the organization; to show the strength of association between dispositional variables and how organization members are rated in general, these correlations can be divided by the square root of the perceiver ICC. In the present study, this means that the relationships between dispositional characteristics and how others in the organization are rated in general are estimated to be $62 \%$ larger than the relationships we report between dispositional characteristics and how single targets are rated. For instance, the -0.25 correlation we found between self-perceptions of being angry/hostile and positive ratings of a single peer would correspond to an expected $-0.25 \sqrt{ } 0.38=-0.40$ correlation between self-perceptions of being angry/hostile and how positively others in the organization are judged in general.

We first examined how positive perceptions of others was related to gender and found that women were considerably more likely to rate a single target positively than were men $(r=0.22)$. However, given that participants invariably rated targets of their own gender in the present study, this could be due either to differences in how men and women rate others (i.e., women may tend to rate any target more positively) or to real differences between men and women (i.e., women may tend to be perceived by raters of either gender more positively than are men). Due to the inability to disentangle these explanations without cross-gender ratings, we controlled for gender in all remaining analyses, so that relationships between positivity and other dispositional characteristics may be more easily interpreted independent of the confounds of the gender of the raters and of the targets rated.

Personality traits. We report the relationship between the positivity of perceptions of others and self-ratings of personality separately for each Big Five domain.

Within the domain of extraversion, the positivity of perceptions of others was consistently associated with self-ratings indicating positive affectivity (e.g., happy/joyful, enthusiastic/excited). Other aspects of extraversion more indicative of sociability or agentic behavior were generally unassociated with positive judgments of others.

There were consistent strong associations between aspects of agreeableness and conscientiousness and the positivity of judgments of others. Tendencies to judge others positively were associated with every dimension related to agreeableness, with the strongest relationships observed for characteristics associated with adversarial behavior (e.g., unsympathetic/unfriendly, angry/hostile). Similarly, most aspects of self-rated conscientiousness were associated with the positivity of perceptions of others, with the strongest effects for dependability.

The positivity of perceptions of others was also associated with some aspects of emotional stability and openness. Individuals who described others more positively tended to describe themselves as less unstable/disturbed and crabby/ grouchy, whereas aspects concerning anxiety or confidence showed no significant associations. Within the domain of openness to experience, the positivity of perceptions of others was associated with evaluating oneself as more intelligent/smart and less narrow-minded/close-minded, but was not significantly associated with other aspects of openness.

Many self-ratings that were relatively unassociated with the Big Five were also associated with positive ratings of others: Individuals who described themselves as well-liked/likeable, great/wonderful, and extraordinary/exceptional, and as less $\mathrm{bad} / \mathrm{immoral}$, annoying/aggravating, and $\mathrm{dumb} / \mathrm{stupid}$ tended to rate others more positively. 
Table 3

Correlations between Positivity of Perceptions of Others and Dispositional Variables in a Dormitory Sample (Study 2)

\begin{tabular}{|c|c|c|c|c|}
\hline Measure and item & $\begin{array}{c}\text { Big Five } \\
\text { associations }\end{array}$ & $\begin{array}{l}r \text { between self-rating } \\
\text { and Positivity factor }\end{array}$ & $\begin{array}{c}\text { Perceiver intraclass } \\
\text { correlation }\end{array}$ & $\begin{array}{l}\text { Loading on } \\
\text { Positivity factor }\end{array}$ \\
\hline \multicolumn{5}{|c|}{ Inventory of Individual Differences in the Lexicon (IIDL) } \\
\hline Outgoing/extraverted & E & 0.06 & 0.11 & 0.34 \\
\hline Enthusiastic/excited & E & 0.17 & 0.22 & 0.41 \\
\hline Bold/assertive & $\mathrm{E}$ & -0.04 & 0.16 & 0.25 \\
\hline Happy/joyful & E, A, S & 0.23 & 0.26 & 0.46 \\
\hline Loud/noisy & E & -0.02 & -0.03 & 0.04 \\
\hline Energetic/active & $\mathrm{E}$ & 0.15 & 0.21 & 0.37 \\
\hline Funny/amusing & $\mathrm{E}$ & 0.21 & 0.22 & 0.41 \\
\hline Brave/fearless & $\mathrm{E}, \mathrm{O}$ & -0.03 & 0.17 & 0.26 \\
\hline Bashful/shy & $-E,-S$ & 0.00 & 0.06 & -0.21 \\
\hline Kind-hearted/caring & A & 0.22 & 0.23 & 0.44 \\
\hline Thankful/grateful & A & 0.22 & 0.22 & 0.39 \\
\hline Affectionate/passionate & A, E & 0.17 & 0.33 & 0.46 \\
\hline Courteous/polite & A, C & 0.23 & 0.17 & 0.38 \\
\hline Truthful/honest & A & 0.23 & 0.22 & 0.42 \\
\hline Cheerful/good-humored & $\mathrm{A}, \mathrm{E}$ & 0.23 & 0.25 & 0.47 \\
\hline Supportive/encouraging & $\mathrm{A}, \mathrm{E}$ & 0.24 & 0.22 & 0.40 \\
\hline Short-tempered/impatient & $-\mathrm{S},-\mathrm{A}$ & -0.13 & 0.14 & -0.25 \\
\hline Unsympathetic/unfriendly & $-A,-E$ & -0.27 & 0.24 & -0.44 \\
\hline Angry/hostile & $-A,-S$ & -0.25 & 0.21 & -0.36 \\
\hline Conceited/egotistical & $-\mathrm{A}$ & -0.20 & 0.10 & -0.20 \\
\hline Cruel/abusive & $-\mathrm{A}$ & -0.22 & 0.29 & -0.37 \\
\hline Insulting/offensive & $-\mathrm{A}$ & -0.19 & 0.14 & -0.29 \\
\hline Controlling/dominant & $-\mathrm{A}$ & -0.12 & 0.10 & -0.08 \\
\hline Organized/efficient & $\mathrm{C}$ & 0.17 & 0.08 & 0.12 \\
\hline Dependable/reliable & $\mathrm{C}$ & 0.20 & 0.16 & 0.37 \\
\hline Level-headed/sensible & $\mathrm{C}$ & 0.18 & 0.13 & 0.31 \\
\hline Accomplished/successful & $\mathrm{C}, \mathrm{E}$ & 0.14 & 0.28 & 0.50 \\
\hline Competent/capable & C & 0.14 & 0.22 & 0.41 \\
\hline Messy/sloppy & $-\mathrm{C}$ & -0.17 & 0.07 & -0.02 \\
\hline Unreliable/undependable & $-\mathrm{C}$ & -0.23 & 0.20 & -0.32 \\
\hline Childish/immature & $-\mathrm{C}$ & -0.08 & 0.16 & -0.21 \\
\hline Awkward/clumsy & $-C,-S$ & -0.05 & 0.19 & -0.28 \\
\hline Calm/relaxed & $\mathrm{S}$ & 0.11 & 0.16 & 0.26 \\
\hline Confident/self-assured & $\mathrm{S}, \mathrm{E}$ & 0.06 & 0.20 & 0.37 \\
\hline Satisfied/secure & $\mathrm{S}, \mathrm{C}$ & 0.14 & 0.14 & 0.31 \\
\hline Tense/nervous & $-S$ & -0.06 & 0.24 & -0.35 \\
\hline Ashamed/guilt-prone & $-S$ & -0.10 & 0.25 & -0.33 \\
\hline Unstable/disturbed & $-S$ & -0.26 & 0.30 & -0.42 \\
\hline Insecure/unsure & $-S,-E$ & -0.10 & 0.15 & -0.25 \\
\hline Sad/unhappy & $-S_{,}-\mathrm{E},-\mathrm{A}$ & -0.17 & 0.23 & -0.32 \\
\hline Crabby/grouchy & $-\mathrm{S},-\mathrm{A}$ & -0.20 & 0.18 & -0.33 \\
\hline Lonely/lonesome & $-S$ & -0.18 & 0.20 & -0.35 \\
\hline Creative/artistic & $\mathrm{O}$ & 0.04 & 0.24 & 0.28 \\
\hline Intelligent/smart & $\mathrm{O}$ & 0.15 & 0.26 & 0.42 \\
\hline Complex/deep & $\mathrm{O}$ & 0.01 & 0.24 & 0.21 \\
\hline Skilled/talented & $\mathrm{O}$ & 0.08 & 0.28 & 0.47 \\
\hline Traditional/conventional & $-\mathrm{O}$ & 0.09 & 0.10 & 0.16 \\
\hline Narrow-minded/close-minded & $-\mathrm{O},-\mathrm{A}$ & -0.14 & 0.16 & -0.26 \\
\hline Prominent/well-known & $\mathrm{E}$ & 0.01 & 0.21 & 0.26 \\
\hline Well-liked/likeable & E, A & 0.21 & 0.16 & 0.39 \\
\hline Great/wonderful & E & 0.10 & 0.32 & 0.55 \\
\hline Weird/strange & $-\mathrm{C}$ & -0.06 & 0.27 & -0.24 \\
\hline Attractive/good-looking & $\mathrm{E}$ & 0.01 & - & - \\
\hline Annoying/aggravating & - & -0.20 & 0.16 & -0.28 \\
\hline Bad/immoral & - & -0.26 & 0.25 & -0.39 \\
\hline Dumb/stupid & - & -0.16 & 0.22 & -0.39 \\
\hline Extraordinary/exceptional & - & 0.10 & 0.27 & 0.46 \\
\hline Stylish/fashionable & - & 0.05 & 0.26 & 0.36 \\
\hline \multicolumn{5}{|c|}{ Additional variables } \\
\hline Height & - & -0.11 & - & - \\
\hline Religiosity & - & 0.06 & - & - \\
\hline Political orientation & - & 0.01 & - & - \\
\hline
\end{tabular}




$\begin{array}{lcccc}\text { Table } 3 \text { (continued) } & \begin{array}{c}\text { Big Five } \\ \text { associations }\end{array} & \begin{array}{c}r \text { between self-rating } \\ \text { and Positivity factor }\end{array} & \begin{array}{c}\text { Perceiver intraclass } \\ \text { correlation }\end{array} & \begin{array}{c}\text { Loading on } \\ \text { Positivity factor }\end{array} \\ \text { Measure and item } & - & 0.11 & - & - \\ \text { GPA } & - & 0.16 & - & - \\ \text { Average liking from floormates } & - & 0.11 & & - \\ \text { Life satisfaction } & & & - & - \\ & - & -0.12 & - & - \\ \text { Millon Clinical Multiaxial Inventory-III } & - & -0.20 & - & - \\ \text { Narcissism } & - & -0.20 & - & - \\ \text { Paranoid } & - & -0.16 & - & - \\ \text { Antisocial } & - & -0.18 & - & - \\ \text { Avoidant } & - & 0.17 & & -\end{array}$

Note. All analyses are based on at least 913 observer ratings from at least 353 raters; all correlations are conducted controlling for gender. The "Big Five associations" column shows all Big Five inventory scales that have correlations of at least $|r|=0.30$ with the item from a previous investigation, where $\mathrm{E}=$ extraversion, $\mathrm{A}=$ agreeableness, $\mathrm{C}=$ conscientiousness, $\mathrm{S}=$ emotional stability, $\mathrm{O}=$ openness to experience (with scales listed in descending order of highest to lowest correlations). Negative signs (e.g., "-S") indicate that the item is negatively associated with the Big Five dimension. Values in bold indicate (a) same-trait perceiver effects greater than 0.20 and factor loadings greater than 0.30 , as well as (b) all statistically significant correlations $(p<0.05)$ between self-rated IIDL items and the positivity factor. Dashes indicate missing values.

Personality disorders. We next examined how the MCMI-III measures of personality disorders were associated with the positivity of perceptions of others. These correlations are shown in Table 3. Most of the personality disorders showed the same general pattern of relationships, in which higher scores on personality disorders were associated with judging targets less positively. This pattern was found for the MCMI-III measures of narcissistic, paranoid, antisocial, avoidant, and borderline personality disorders. The associations were similar in magnitude across these disorder scales, with the personality disorder measure showing associations of approximately $|r|=0.15$ with how positively others were judged. Only the MCMI-III measure of obsessive-compulsive tendencies showed a different pattern, which was the reverse of the general pattern: Higher levels of obsessive-compulsive tendencies were associated with more positive judgments of others $(r \mathrm{~s}=0.17)$.

Additional variables. We explored the relationship between perceiver effects and height, religiosity, political orientation, GPA, life satisfaction, and how much the person was liked by dormitory floormates. We found that taller raters tended to rate targets less positively $(r s=-0.11)$. As in Study 1 , selfreported GPA was associated with more positive ratings of others $(r=0.11)$. Reports of life satisfaction were also associated with seeing others more positively $(r=0.11)$. Finally, as might be expected, individuals who rated targets on their floor more positively tended to be rated as more likable by their floormates ( $r s=0.16)$.

\section{Discussion}

The factor analysis results of Study 2 indicate that the structure of perceiver effects is decidedly simpler than the structure of self-ratings or ratings of single peers. In particular, the results suggest that a single factor concerning how positively others are perceived is sufficient to capture most of the covariation in how individuals tend to see others across a broad range of traits. This dimension was found when examining a suite of traits that are relatively distinct at the level of self-reports or single-peer reports. The single-perceivereffect dimension reflects the extent to which other people are seen as interesting, impressive, trustworthy, friendly, happy, and emotionally stable. The fact that we were unable to identify even two relatively orthogonal dimensions of perceiver effects suggests that people have relatively undifferentiated rater biases, as manifested in how they generally tend to rate others.

How positively individuals rated others also showed sizable relationships with a number of dispositional variables. Describing others as interesting, happy, and possessing fewer antisocial tendencies was associated with a host of characteristics indicative of good emotional functioning (e.g., happiness, life satisfaction, and emotional stability) and positive relations with others (e.g., friendliness and courtesy vs. hostility and undependability), as well as more desirable selfevaluations (e.g., self-perceptions of being likable and great). Given that the tendency to perceive others positively could be simply a scale-use bias, it is important to note that positive perceptions of others correlated with a number of measures that should be less susceptible to the scale-use biases that might infuse abstract trait ratings. As in Study 1, individuals who saw others more positively tended to report a higher GPA. Further, individuals were more likely to rate others positively if they were shorter and female and if others on the floor rated them as likable. These effects strongly suggest that correlations between the perceived positivity of others and other dispositional variables are not entirely driven by scale-use differences.

\section{Study 3: Stability of Perceiver Effects}

In this final study, we focused on three questions. Using a different data set, in which perceiver effects were estimated through ratings by members of the participants' fraternity or sorority, we conducted new factor analyses to examine whether the factor structure of perceiver effects identified in Study 2 could be identified in a new data set with different items. Second, we conducted analyses linking perceiver-effect dimensions to a broader array of dispositional variables, including self- and peer-ratings of personality traits, well-being measures, and attitudes about power. Given that perceiver effects are operationalized as perceptions by members of a defined group and reflect a person's average ratings of a person in that context, we also explored how perceiver 
effects were associated with the participants' overall experience with that group. Third, we explored the stability of perceiver effects over a year to examine whether the stability of perceiver effects might be comparable to other dispositional variables.

\section{Method}

Participants and procedure. A total of 366 participants were recruited from seven different fraternities and sororities at the University of Illinois at Urbana-Champaign. A total of 203 women were recruited from three sororities, and 163 men were recruited from four fraternities. The participation from each organization ranged from 34 members in one fraternity to 75 in two sororities. Participants completed the survey at the organization's house, usually in the span of about $2 \mathrm{hr}$. Only fraternities and sororities that were housed on campus were approached, given our desire to examine settings where members were already acquainted. Participants were given $\$ 10$ for completing the first administration of the survey and were given an additional \$20 if they completed the second administration of the study a year later. The organization was also given money for its assistance with the study; the amount varied as a function of the size of the organization and the percentage of participating members. Organizations and their members were told that the answers they provided would be confidential (i.e., neither the participants nor their organizations would be identified when information concerning the study was shared with others).

Personality trait ratings of self and others. Participants completed an inventory containing 75 adjectives, which included a set of 53 adjectives designed to measure the Big Five (Walton \& Roberts, 2004) and a number of terms selected to measure subclinical psychopathy, narcissism, and Machiavellianism (the "Dark Triad;" Harms, Wood, Brummel, \& Roberts, 2010). Participants completed self-ratings with the prompt "How do you see yourself in general?" and with response options ranging from 1 (Strongly disagree) to 5 (Strongly agree). Items were presented to participants alphabetically.

After completing all other survey materials, participants were asked to rate the personalities of three other members of their organization on the same 75-item trait inventory. The members they were assigned to rate were randomly selected, with the only constraint being that people were more likely to rate individuals of their own year or adjacent years (e.g., seniors were unlikely to rate freshmen, and vice versa). Because assignments of targets to raters were near-random, sometimes raters were asked to rate individuals they did not know or to complete observer reports of themselves. If either of these situations occurred, individuals were asked to return their form to the experimenter and were then given another, randomly selected target to rate. Finally, some participants completed observer reports inappropriately by copying their answers from a previous form. We identified these individuals by performing a profile correlation across their answers. If the profile correlation between two ratings by the same rater approached unity (i.e., $r>0.99$ ), we excluded all of the person's observer ratings. A total of 908 ratings were included in the analysis from 323 different raters.

In addition to using these observer reports for examination of properties of perceiver effects, we also averaged observer reports that were made of the same individual to see whether an individual's perceiver effects were associated with how they were seen by others. Each participant was rated by an average of 2.1 raters, and the overall reliability of observer reports of personality based on interrater agreement and this number of raters using the Spearman-Brown prophecy formula was estimated at 0.55 for extraversion, 0.41 for agreeableness, 0.43 for conscientiousness, and 0.41 for emotional stability, and 0.25 for openness. For the relationships we report between perceiver effects and how the individuals were rated by peers on Big Five characteristics, the aggregate peer ratings have been corrected for unreliability, and consequently the correlations should be interpreted as the relationship between the positivity of a participant's ratings of a single target and the individual's reputation in the organization in general.

\section{Other Individual Difference Measures}

Hope for and fear of power. Participants completed sixitem versions of the Hope for Power and Fear of Power scales (Harms, Roberts, \& Wood, 2007). The item with the highest item-total correlation with the Hope for Power scale was "I am driven to become as powerful as possible" $(\alpha=0.80)$. The item with the highest item-total correlation with the Fear of Power scale was "The thought of being put in a position of authority scares me" $(\alpha=0.80)$.

Social dominance orientation. Participants completed an eight-item version of the Social Dominance Orientation Scale, which assesses belief in and comfort with group inequalities (Pratto, Sidanius, Stallworth, \& Malle, 1994, p. 757). The item with the highest item-total correlations was "It is important that we treat other countries as equals" (RS; $\alpha=0.82$ ).

Misuse of power. Participants also completed the eightitem Misuse of Power scale (Lee-Chai, Chen, \& Chartrand, 2001). This scale assesses how acceptable participants feel it is to misuse their power and status $(\alpha=0.66)$.

Well-being. To assess well-being, we administered the fiveitem Satisfaction with Life Scale (Pavot \& Diener, 1993; a = 0.84 ) and the 20-item Center for Epidemiological Studies-Depression scale (Radloff, 1977; $a=0.88$ ).

General fit with peers. Participants rated these two items indicating their fit with others who were their age: "I feel that I fit in with people my age" and "I feel that I fit in with my peers" $(\alpha=0.81)$.

Satisfaction with organization. Satisfaction with the organization was measured with the items "On the whole, being in this [fraternity/sorority] is dissatisfying to me" (RS) and "Overall, I am satisfied with being in this [fraternity/sorority]" $(\alpha=0.89)$.

Perceived capacity for power. A five-item version of Anderson, John, and Keltner's (2009) Personal Sense of Power scale was included in the present sample. The scale assesses the extent to which members believe they can be heard by and influence other members of their organization $(\alpha=0.74)$.

Organization identity goals. A six-item scale was included that assessed a person's desire to identify and be recognized as a member of his or her organization. Items with the highest item- total correlations were "I want to be recognized as a member of this [fraternity/sorority] by outsiders" and "I want to be a member of this [fraternity/sorority]" ( $\alpha=0.87)$. Peer-rated liking, knowledge, and influence. Participants 
rated the extent to which they knew and liked every other member in their organization and were also asked to rate the level of influence each member had over organization decisions. After removing self-ratings, we aggregated these ratings to estimate how much each person was seen as liked, known, and had status as rated by the person's peers. By estimating ICCs from a linear mixed model, we found the interrater agreement to be 0.15 for liking ratings, 0.22 for ratings of how much members were known by the rater, and 0.35 for influence ratings. Because participants were rated by an average of 28 other people, the reliability of these estimates for the average participant for all dimensions was expected to exceed 0.83 .

Modeling the stability of perceiver effects. The stability of perceiver effects was estimated by creating a separate file for each trait that contained three columns consisting of the rater's identification number, the year the rating was collected, and the score that the rater gave the target on that trait. In turn, a linear mixed model was constructed in which main effects of the 2 years were specified as fixed predictors and random effects for these variables were specified to allow people to have different variances across raters for ratings provided in Year $1\left(\tau_{11}\right)$ and Year $2\left(\tau_{22}\right)$; an unstructured covariance matrix was specified such that these random effects were freely allowed to covary $\left(\tau_{12}\right)$; the model is shown in Figure 1 .

By using a simple multilevel statistic generally employed to estimate the group-level correlations between variables col- lected among individuals nested in groups (Gonzalez \& Griffin, 2002; Raudenbush \& Bryk, 2002), we combined these variances and covariances to estimate the latent stability of perceiver effects over time. By dividing the covariance of Year 1 and Year 2 random effects (12) by the square root of the variances for those years (11 and 22), we estimated the level of rank-order stability that should be expected between reliably estimated perceiver effects over a year. In other words, this stability coefficient allowed us to estimate how much perceiver-effect estimates collected in different years would correlate if we had individuals rate a large number of targets one year and a large number of different targets a year later. As applied to the overall positivity of ratings, this allowed us to estimate the extent to which we expected raters who generally rated targets particularly positively or negatively one year to continue to rate targets particularly positively or negatively a year later.

Note that the formulas given in Figure 1 estimate the correlation in which the individuals rate several targets but never rate any particular target twice. We thus eliminated peer ratings in which a participant rated the same target in both years of the survey by randomly eliminating one of their Year 1 or Year 2 ratings of a target they rated twice. Failing to do so would be expected to artificially influence estimates of the longitudinal stability of perceiver effects by making stabilities in perceivers' ratings a function of not just perceiver effects but also relationship and target effects.

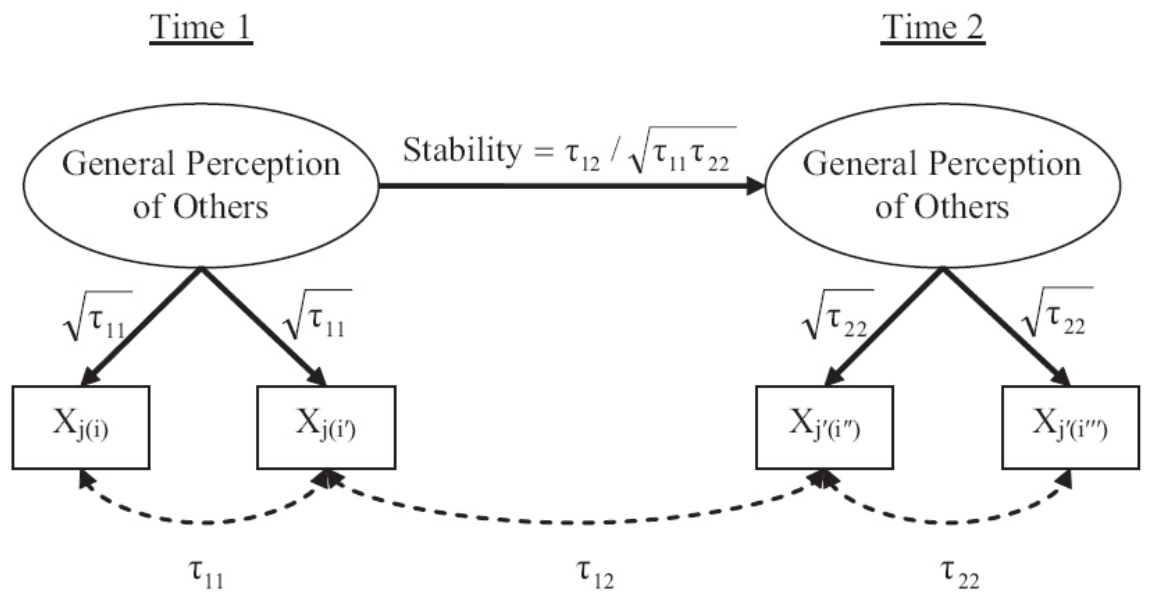

Variances $\tau_{11}$ and $\tau_{22}$ and covariance $\tau_{21}$ are obtained from this linear mixed model:

$$
\begin{aligned}
\text { Rating }_{\mathrm{ijk}} & =\mathrm{b}_{1 \mathrm{k}}\left(\text { Year }_{1}\right)+\mathrm{b}_{2 \mathrm{k}}\left(\text { Year }_{2}\right)+\mathrm{r}_{\mathrm{ijk}} \\
\mathrm{i} & =\text { target, } \mathrm{j}=\text { year of assessment, } \mathrm{k}=\text { rater } \\
& \mathrm{b}_{1 \mathrm{j}}=r_{1}+u_{1 \mathrm{k}^{\prime}}, \mathrm{b}_{2 \mathrm{j}}=\gamma 2+u_{2 \mathrm{k}^{\prime}}, \mathrm{r}_{\mathrm{ijk}} \sim \mathrm{N}\left(0, \sigma_{\mathrm{r}}^{2}\right) \\
& \hat{\operatorname{var}}\left[\begin{array}{l}
u_{1 \mathrm{k}} \\
u_{2 \mathrm{k}}
\end{array}\right]=\left[\begin{array}{ll}
\hat{\tau}_{11} & \hat{\tau}_{12} \\
\hat{\tau}_{12} & \hat{\tau}_{22}
\end{array}\right]
\end{aligned}
$$

Figure 1. Modeling the stability of perceiver effects. 
Results

Relation between self-ratings and perceiver effects for Big Five traits. As in the two earlier studies, we once again began by exploring the relationship between self-ratings and perceiver effects on the Big Five traits. These are shown in the bottom right side of Table 1 . Similar to results from the previous two studies, assumed similarity effects were found for all Big Five traits except extraversion ( $r s \geq 0.11$ ), but there were also numerous associations on the off-diagonals of the correlation matrix. Self-ratings of agreeableness were significantly associated with judging others more positively along every Big Five dimension ( $r$ s between 0.09 and $0.21 ; p s<0.05$ ) and in most cases showed higher correlations with perceiver effects than did the correlation for the assumed similarity effect for the same trait. Interestingly, as in Study 1, extraversion was associated with perceiving others more positively along every Big Five dimension except extraversion (all $r s \geq 0.10$; $p s \leq$ 0.05 ), and openness self-ratings were associated with perceiving others more positively across all Big Five dimensions.

Covariation among Big Five perceiver effects. We again examined the extent to which a rater's judgments of a target's traits were associated with the same rater's judgments of the same and different characteristics in a different target. As can be seen in the bottom left side of Table 1, and as was found in Study 2, the cross-class correlations between trait perceiver effects differed substantially from zero and were nearly the same size as the perceiver ICCs. In fact, the average crossclass correlation of the perceiver effects for Big Five traits was 0.16 , whereas the average ICC was 0.20 , indicating that crossclass correlations were more than $80 \%$ of the size of ICCs. As in Study 2, this indicates that the perceiver effects for different Big Five traits were highly associated with one another.

Structure of perceiver effects. As in Study 2, we conducted a factor analysis on the square symmetric correlation matrix that can be constructed by correlating all pairs of ratings that a rater provided of different targets (i.e., correlating the ratings an individual made of target $i$ with the ratings the individual made of a different target $\left.i^{\prime}\right)$. Given the fact that the 13 adjectives beginning with un- (e.g., "unintelligent," "uncreative") appeared to elicit acquiescence or satisficing biases (e.g., some participants provided the same value for all 13 items), we chose to exclude these terms from the analysis, resulting in a total of 62 items.

We then conducted a factor analysis on the perceiver-effect matrix using principal axis factor extraction with varimax rotations. The first 10 eigenvalues from the matrix were 5.9, 2.1, $1.5,1.4,1.3,1.3,1.2,1.2,1.2$, and 1.1. These results again strongly pointed to a one-factor or two-factor solution; these were investigated in more detail. First, in the two-factor solution the highest loading items on the rotated first factor were jealous, manipulative, harsh, fretful, insensitive, deceitful, anxious, envious, and abusive (all loadings between 0.41 and 0.38), and on the second rotated factor the highest loading items were relaxed, intellectual, energetic, creative, attractive, practical, warm, and imaginative (all loadings between 0.35 and 0.29). Despite the differences in the item pools, the two factors looked fairly similar to the dimensions identified in Study 2, reflecting perceptions of others as possessing negative/antisocial and positive/impressive characteristics, respectively. However, as in Study 2, analyses conducted using scores from the two-factor solution demonstrated that when scale scores of the two dimensions were created, scores on the two perceiver-effect dimensions were high- ly intercorrelated and that relations with dispositional variables mirrored each other. The column-vector correlations of the two scales for the variables used in Table 4 was $r=-0.94$, indicating that traits that correlated with one dimension would correlate roughly with the same magnitude and in the opposite direction with the second dimension. Given the failure of the two dimensions to show discriminant patterns of associations with disposition, we focused on the one-factor solution.

As in Study 2, the first unrotated factor served to combine the two factors into an overall positivity dimension representing a contrast of positive versus negative perceptions. The highest loading negative items were jealous, insensitive, abusive, cold, inefficient, harsh, envious, anxious, greedy, and deceitful (all loadings between 0.45 and 0.39), and the highest loading positive items were kind, energetic, talkative, sympathetic, attractive, imaginative, honest, trustful, creative, and warm (all loadings between -0.38 and -0.32 ). We created scores by averaging these 20 items after reverse-coding the negative items. As in Study 2, scores on this dimension thus represented how much people saw others as trustworthy, nice, interesting, and possessing other positive characteristics. We again estimated the perceiver ICC for this dimension. This correlation was estimated at 0.35 , very close to the size of the similar dimension in Study 2.

Table 4

Correlations Between Positivity of Perceptions of Others and Dispositional Variables in Greek Organizations (Study 3)

$$
\begin{gathered}
\text { Measure Rated positivity of target } \\
\text { General dispositional measures }
\end{gathered}
$$

Self-rated personality

\begin{tabular}{lc} 
Extraversion & $\mathbf{0 . 1 1}$ \\
Agreeableness & $\mathbf{0 . 3 3}$ \\
Conscientiousness & $\mathbf{0 . 1 4}$ \\
Emotional stability & $\mathbf{0 . 1 8}$ \\
Openness & $\mathbf{0 . 1 6}$ \\
Peer-rated personality & \\
Extraversion & -0.08 \\
Agreeableness & $\mathbf{0 . 1 3}$ \\
Conscientiousness & $\mathbf{0 . 2 2}$ \\
Emotional stability & $\mathbf{0 . 1 5}$ \\
Openness & 0.13 \\
Additional measures & \\
Age & -0.04 \\
ACT Assessment score & $\mathbf{0 . 1 0}$ \\
How religious & $\mathbf{0 . 0 7}$ \\
How liberal/conservative & -0.03 \\
Fear of Power scale & $\mathbf{- 0 . 1 1}$ \\
Need for Power scale & $\mathbf{- 0 . 2 0}$ \\
Social Dominance Orientation Scale & $\mathbf{- 0 . 2 1}$ \\
Misuse of Power scale & $\mathbf{- 0 . 2 2}$ \\
General fit with peers & $\mathbf{0 . 2 0}$ \\
CES-Depression scale & $\mathbf{0 . 1 8}$ \\
Satisfaction with Life Scale & $\mathbf{0 . 2 1}$ \\
Organization identity goals & $\mathbf{0 . 3 2}$ \\
Organization satisfaction & $\mathbf{0 . 3 1}$ \\
Personal Sense of Power scale & $\mathbf{0 . 2 4}$ \\
Average rated influence & 0.04 \\
Average rated knowledge & 0.04 \\
Average rated liking & $\mathbf{0 . 1 4}$ \\
\hline
\end{tabular}

Note. All correlations are based on at least 802 ratings from at least 302 raters, except for correlations using peer reports of participant's personality, which are based on 794 ratings from 279 raters. All statistically significant correlations $(p<0.05)$ are shown in bold. The organization of the rater is controlled for all correlations. ACT $=$ American College Testing; CES = Center for Epidemiological Studies. 
Correlates of the positivity of perceptions of others. We next investigated the relationships between positive perceptions of others and dispositional variables. To compensate for the fact that participants rated targets only within their organization, we controlled for the organization of the rater in all analyses. Because all organizations were single-sex and raters rated members of only their organization, controlling for the organization of rater simultaneously controlled for the gender of the rater and target. Again, the correlations that are reported show how dispositional variables are associated with positive perceptions of a single other member of the organization; to show the strength of association between dispositional variables and how others in the organization are perceived in general, these correlations can be divided by the square root of the perceiver ICC.

As can be seen in Table 4, there were various relationships between how individuals saw others and their dispositional characteristics. First, individuals who perceived others more positively tended to report higher levels of extraversion, conscientiousness, emotional stability, openness, and especially agreeableness. In addition, positive perceptions of others correlated with how the raters were judged by others. Individuals who perceived others more positively tended to be judged by others as significantly more agreeable, conscientious, and emotionally stable.

Individuals who perceived others positively tended to report a greater sense of fitting in with their same-age peers, higher life satisfaction, lower depression, and higher ACT scores. Having positive perceptions of others was also related to having a lowered desire to have power over others, less fear of being in a position of power, a lower sense that it is acceptable to misuse power, and a lower social dominance orientation (i.e., belief in the superiority of some groups over others).

Finally, having positive perceptions of others was also associated with having considerably better organizational experiences. People who identified with their organization and reported that they were satisfied and had status in the organization were considerably more likely to describe members of their organization as possessing positive traits (all |rs | between 0.24 and 0.32 ). As in Study 2, rating others positively was also associated with being rated as more likable by others in the organization $(r=0.14)$.

Longitudinal stability of perceived positivity of others. Finally, we estimated the stability of perceived positivity of others using the linear mixed model design described in the Method section and outlined in Figure 1. This analysis was based on 892 ratings from 158 participants who provided ratings of other organization members in both years. From this linear mixed model, the variance of observer ratings due to rater differences was estimated to be 0.0867 in Year $1\left(\tau_{11}\right)$, and 0.0849 in Year $2\left(\tau_{22}\right)$. In contrast, the covariance between Year 1 and Year 2 observer ratings due to rater differences $\left(\tau_{12}\right)$ was estimated to be 0.0594 . Using the equations shown in Figure 1, we estimated the stability of perceiver effects over the course of a year to be a correlation of 0.69 . This value indicates that the average positivity of a person's perceptions of a large number of people during one year (averaged across many ratings to form a reliable estimate) would be expected to correlate quite highly with the average positivity of the person's perceptions a year later.
Discussion

Using a different sample and pool of lexical terms, we again found that a single positivity factor could adequately account for the covariation in perceiver effects on a broad range of traits. This single dimension looked much like the positivity dimension identified in Study 2; that is, it reflected the tendency to perceive people as trustworthy, nice, interesting, and emotionally stable. Further, the correlation between the positivity of an individual's judgments of two different targets was fairly large, indicating that there are sizable individual differences in how positively other targets are judged. As in the first two studies, we found that variation in perceiver effects correlated in sensible ways with dispositional variables, ranging from academic performance and being liked by others to selfand peer-reported personality traits, organizational experiences, and well-being measures. Finally, our analyses suggest that the individual differences in tendencies to rate others positively showed an impressive level of stability over a year.

\section{General Discussion}

The results of the studies presented here indicate that how we perceive others in our social environments reveals much about our personality. First, the studies clearly demonstrate that perceiver effects represent more than simply the projection of an individual's self-image onto other people. For instance, in none of the three studies did self-rated extraversion show a statistically significant relationship with perceiving others as extraverted, despite the fact that self-rated extraversion was regularly associated with perceiving others as possessing a range of other positive characteristics. Similarly, self-rated agreeableness was associated with seeing others as more agreeable but also as possessing a host of other positive characteristics.

Our investigation also served to follow up on recent findings that suggest that perceiver effects may have fewer orthogonal factors than do self-ratings (Beer \& Watson, 2008a; Srivastava et al., 2010). Instead of identifying five factors, our analyses suggested that a single-factor model could effectively capture most of the covariation in how individuals perceived different targets along different traits. The magnitude of individual differences in the positivity of perceptions of others is fairly large, and individual differences in perceiver positivity impacted judgments of single targets to a considerable degree.

Further, we found that individual differences in the positivity of perceptions of others show a level of stability comparable to that of other personality dimensions: approximately 0.69 over the period of a year. It is worth noting that the stability of perceiver effects reported here was higher than the stabilities of 0.20 to 0.50 reported in past studies (Malloy et al., 1995; Srivastava et al., 2010). The most likely reason for this discrepancy is undoubtedly that latent stabilities were reported here, which correspond to expected stability of perceiver effects if we had averaged a large number of ratings of others. In contrast, previous investigations of perceiver-effect stability examined the rank-order stability of perceiver-effect estimates created by averaging a small number of rater judgments (between three and eight), which should serve to make the perceiver-effect estimates quite unreliable and which should lead to lower stability estimates even if both measurement occasions occurred nearly contemporaneously. The im- 
plication that judgments of others completed a year apart correlated only slightly less than did judgments completed contemporaneously is somewhat surprising, given the potential for perceiver effects to be driven by mood effects or other session-specific effects. Our finding concerning the high stability of perceiver effects further suggests that how positively we tend to perceive others in our social environment is an important traitlike individual difference in its own right.

The next question we explored was how perceptions of others correlated with dispositional characteristics. This is important because, in many frameworks, our perceptions of others are thought to be an important cause of our behavior (e.g., Dodge \& Crick, 1990; Kelly, 1963; Reis, 2008). In each study, we found regular relationships between personality traits and perceptions of others. Individuals who perceived others positively reported higher agreeableness (particularly aspects associated with friendliness and low hostility); higher life satisfaction; and lower endorsement of measures of personality disorders, depression, and antisocial attitudes. Individuals who perceived others more positively also tended to be more liked by others from the group they rated, and they described their experiences in the group more positively. The causal direction of these associations is unclear and should be explored in future research. However, the results clearly indicate that how positively we perceive others in a group shows important relationships with our general emotions, well-being, goals, values, and attitudes, in addition to our group experiences.

The associations between perceiver effects and personality disorders were particularly interesting. Although theorists often discuss how each personality disorder may have its own specific set of cognitive biases (Beck et al., 2004), we found that several personality disorders were associated with a single dimension concerning how generally positively others were perceived. If perceiving others less positively is associated with several personality disorders, this has two important implications for the understanding of personality disorders. First, this may indicate that perceiving others as being unfriendly, untrustworthy, unhappy, and uninteresting may be a relatively coordinated set of negative cognitions that acts as a common cause to several personality disorders. If so, this may help to explain the phenomenon of comorbidity, in which individuals are much more likely to be diagnosable with several personality disorders simultaneously than would be expected by chance (e.g., Widiger et al., 1991). Second, if negative perceptions of others underlie several personality disorders simultaneously, then finding techniques to get people to see others more positively could promote the cessation of behavior patterns associated with several different personality disorders simultaneously.

\section{Limitations and Future Directions}

The current investigation leaves a number of important questions for future research. Although perceiving others positively was associated with a range of dispositional characteristics, an understanding of the relations between perceiver effects and other individual differences will be improved by obtaining a broader range of individual difference measures. Importantly, the majority of the individual difference variables that were linked to perceptions of others were self-reported and thus could be linked to perceptions of oth- ers through standard response sets, such as social desirability. For instance, although academic achievement was determined through registrar records in Study 1, it was measured through self-reported GPA or scores on standardized tests in the remaining studies. Although these self-reports are highly predictive of actual scores, they have nonetheless been linked to self-enhancement biases relative to official records (Gramzow \& Willard, 2006). The fact that perceiver effects correlated with how much people are liked by others and how their personality is perceived by others (Studies 2 and 3) makes clear that perceiver-effect relationships are not due solely to measurement artifacts of self-reports; however, future investigations should extend efforts to link perceiver effects to non-self-report measures. Researchers should also explicitly examine the link between positive perceptions of others and standard measures of social desirability or selfenhancement biases.

In our investigation, we found that perceiver effects for a wide range of traits could be explained adequately by a single factor. In fact, despite the fact that multiple factors could be extracted, our explorations found that all such factors tended to display similar patterns of associations with dispositional variables. In contrast, a recent investigation conducted by Srivastava and colleagues (2010) presented more optimistic evidence for distinguishable dimensions of perceiver effects beyond an overall evaluation factor. Although the structure of perceiver effects was not the primary focus of the current investigation, the search for perceiver-effect dimensions beyond overall positivity is an interesting question for future research. Given that theorists generally postulate a more complex set of cognitive biases associated with the perception of others than a single positivity dimension (e.g., Beck et al., 2004; Kelly, 1963), future investigators should continue examining whether a larger number of distinct perceiver dimensions can be identified that show clearly distinct patterns of dispositional correlates.

Our findings concerning the structure of perceiver effects and the associations between perceiver effects and other individual differences were quite similar across studies, despite the fact that the targets of perception ranged from friends and fellow organization members to people randomly assigned to one's dormitory. However, it is fair to say that all of these contexts can be thought of as representing how the individual sees ingroup members to varying degrees. Given that previous studies have shown that perceiver effects for ingroup and outgroup members can be fairly distinct from one another (e.g., Boldry \& Kashy, 1999), future studies might explore the dispositional correlates of perceiver effects collected from perceptions of others in a broader range of theoretically meaningful contexts, such as outgroup members, strangers, members of the opposite sex, and superiors versus subordinates. Such studies could help reveal some of the distinct patterns of perceiver-effect associations with different behavioral tendencies that have been proposed by others.

Given that the present investigation was initiated first and foremost to show the relations between perceptions of others and dispositional characteristics, a limitation of the current research is that the design of the studies did not allow for adequate tests of the causal direction of the relationships identified. Our results do not indicate, for instance, whether 
perceiving others more positively causes people to become friendlier and less aggressive toward others, more satisfied with their lives, and more well-liked - or whether having these characteristics causes people to see others more positively. We suspect that the causal effect most likely goes in both directions, and testing the causal links will require the collection of more intensive longitudinal data. We are optimistic that future research will demonstrate the power of perceiver effects to direct the development of these dispositions for at least two reasons. First, the current findings demonstrate the existence of moderate associations between positive perceptions of others and dispositional variables ranging from self-reported personality traits to well-being, mental health, and social functioning measures. Second, in our longitudinal analyses, individual differences in how positively others were rated showed a high level of stability. Stability of environments has been identified as a characteristic that should lead to a greater potential for environments to cause dispositional change (Roberts et al., 2008).

The current research represents a major step in understanding the nature of perceiver effects relative to past approaches, which have largely focused on assumed similarity explanations for understanding perceiver effects. The results of the current studies provide compelling evidence that individuals' perceptions of others can reveal much more than merely how the individuals see themselves on the same characteristics. Specifically, their perceptions of others reveal information about their other personality characteristics, their wellbeing, their mental health, their social attitudes, and how they are judged by others. There are many questions that remain to be answered to demonstrate that one's perceptions of others truly direct developmental outcomes in the manner suggested by some theorists. However, the findings presented here suggest that the emphasis that various models have placed on perceptions of others as determinants of behavior may be well placed and is a fertile place for future research.

\section{References}

American Psychiatric Association. (1994). Diagnostic and Statistical Manual of Mental Disorders (4th ed.). Washington, D.C.: American Psychiatric Association.

Ames, D.R., P. Rose \& C.P. Anderson (2006). The NPI-16 as a short measure of narcissism. Journal of Research in Personality 40: 440-450.

Anderson, C., O.P. John \& D. Keltner (2009). The Subjective Sense of Power: Structure and Antecedents. Unpublished manuscript, University of California, Berkeley.

Back, M.D., J.M. Stopfer, S. Vazire, S. Gaddis, S.C. Schmukle, B. Egloff \& S.D. Gosling (in press). Facebook profiles reflect actual personality not self-idealization. Psychological Science.

Beck, A., A. Butler, G. Brown, K. Dahlsgaard, C. Newman \& J. Beck (2001). Dysfunctional beliefs discriminate personality disorders. Behaviour Research and Therapy 39: 1,213-1,225.

Beck, A. T., A. Freeman \& D.D. Davis (2004). Cognitive Therapy of Personality Disorders (2nd ed.). New York, N.Y.: Guilford Press.

Beck, A., W. Rial \& K. Rickels (1974). Short form of Depression Inventory: Cross-validation. Psychological Reports 34: 1,184-1,186.

Beer, A., \& D. Watson (2008a). Asymmetry in judgments of personality: others are less differentiated than the self. Journal of Personality 76: 535-559.

Beer, A., \& D. Watson (2008b). Personality judgment at zero acquaintance: Agreement, assumed similarity, and implicit simplicity. Journal of Personality Assessment 90: 250-260.

Boldry, J., \& D. Kashy (1999). Intergroup perception in naturally occurring groups of differential status: a social relations perspective.
Journal of Personality and Social Psychology 77: 1,200-1,212.

Campbell, D.T., N. Miller, J. Lubetsky \& E.J. O'Connell (1964). Varieties of projection in trait attribution. Psychological Monographs 78 (15, Whole No. 592).

Caprara, G.V., C. Barbaranelli, R.C. Fraley \& M. Vecchione (2007). The simplicity of politicians' personalities across political context: An anomalous replication. International Journal of Psychology 42: 393-405.

Caspi, A., E.S. Herbener \& D.J. Ozer (1992). Shared experiences and the similarity of personalities: a longitudinal study of married couples. Journal of Personality and Social Psychology 62: 281-291.

Christie, R., \& Geis, F. L. (1970). Studies in Machiavellianism. New York, N.Y.: Academic Press.

Cronbach, L.J. (1955). Processes affecting scores on "understanding of others" and "assumed similarity." Psychological Bulletin 52: 177193.

Dodge, K.A., \& N.R. Crick (1990). Social information processing bases of aggressive behavior in children. Personality and Social Psychology Bulletin 53: 1,146-1,158.

Goldberg, L. (1993). The structure of phenotypic personality traits. American Psychologist 48: 26-34.

Gonzalez, R., \& D. Griffin (2000). On the statistics of interdependence: treating dyadic data with respect. In: W. Ickes \& S. Duck (Eds.), The Social Psychology of Personal Relationships (pp. 181-213). New York, N.Y.: Wiley.

Gonzalez, R., \& D. Griffin (2002). Modeling the personality of dyads and groups. Journal of Personality 70: 901-924.

Gosling, S., P. Rentfrow \& W. Swann (2003). A very brief measure of the Big-Five personality domains. Journal of Research in Personality 37: 504-528.

Gramzow, R., \& G. Willard (2006). Exaggerating current and past performance: motivated self-enhancement versus reconstructive memory. Personality and Social Psychology Bulletin 32: 1,114-1,125.

Graziano, W.G., J. Bruce, B.E. Sheese \& R.M. Tobin (2007). Attraction, personality, and prejudice: liking none of the people most of the time. Journal of Personality and Social Psychology 93: 565-582.

Graziano, W.G., \& R.M. Tobin (2002). Agreeableness: dimension of personality or social desirability artifact? Journal of Personality 70: 695-727.

Griffin, D., \& R. Gonzalez (1995). Correlational analysis of dyad-level data in the exchangeable case. Psychological Bulletin 118: 430-439.

Harms, P.D., B.W. Roberts \& D. Wood (2007). Who shall lead? An integrative personality approach to the study of the antecedents of status in informal social organizations. Journal of Research in Personality 41: 689-699.

Harms, P.D., D. Wood, B. Brummel \& B. Roberts (2010). The Minimarkers of Evil. Manuscript in preparation. University of Nebraska-Lincoln.

Hoch, S.J. (1987). Perceived consensus and predictive accuracy: the pros and cons of projection. Journal of Personality and Social Psychology 53: 221-234.

Hoyt, W. (2000). Rater bias in psychological research: when is it a problem and what can we do about it? Psychological Methods 5: 6486.

John, O.P., \& S. Srivastava (1999). The Big Five trait taxonomy: History, measurement, and theoretical perspectives. In: L.A. Pervin \& O.P. John (Eds.), Handbook of Personality: Theory and Research (2nd ed., pp. 102-138). New York, N.Y.: Guilford Press.

Kelly, G.A. (1963). A Theory of Personality: The Psychology of Personal Constructs. New York, N.Y.: Norton.

Kenny, D.A. (1994). Interpersonal Perception: A Social Relations Analysis. New York, N.Y.: Guilford Press.

Kenny, D.A., L. Mannetti, A. Pierro, S. Livi \& D.A. Kashy (2002). The statistical analysis of data from small groups. Journal of Personality and Social Psychology 83: 126-137.

Laing, R.D. (1967). The Politics of Experience. New York, N.Y.: Pantheon.

Lakey, B., \& P.B. Cassady (1990). Cognitive processes in perceived social support. Journal of Personality and Social Psychology 59: 337-343. 
Lee-Chai, A.Y., S. Chen \& T.L. Chartrand (2001). From Moses to Marcos: individual differences in the use and abuse of power. In: A.Y. Lee-Chai \& J.A. Bargh (Eds.), The Use and Abuse of Power (pp. 57-74). Philadelphia, Pa.: Psychology Press.

Malloy, T.E., D.B. Sugarman, R.K. Montvilo \& T. Ben-Zeev (1995). Children's interpersonal perceptions: a social relations analysis of perceiver and target effects. Journal of Personality and Social Psychology 68: 418-426.

Millon, T. (1997). Millon Clinical Multiaxial Inventory-III (MCMI-III): Manual (2nd ed.). Minneapolis, Minn.: National Computer Systems.

Mischel, W., \& Y. Shoda (1995). A cognitive-affective system theory of personality: reconceptualizing situations, dispositions, dynamics, and invariance in personality structure. Psychological Review 102: 246-268.

Pavot, W., \& E. Diener (1993). Review of the Satisfaction with Life Scale. Psychological Assessment 5: 164-172.

Pratto, F., J. Sidanius, L.M. Stallworth \& B.F. Malle (1994). Social dominance orientation: a personality variable predicting social and political attitudes. Journal of Personality and Social Psychology 67: 741-763.

Radloff, L.S. (1977). The CES-D scale: a self-report depression scale for research in the general population. Applied Psychological Measurement 1: 385-401.

Raine, A. (2008). From genes to brain to antisocial behavior. Current Directions in Psychological Science 17: 323-328.

Raudenbush, S.W., \& A.S. Bryk (2002). Hierarchical Linear Models: Applications and Data Analysis Methods. Thousand Oaks, Calif.: Sage.

Ready, R.E., L.A. Clark, D. Watson \& K. Westerhouse (2000). Selfand peer-related personality: agreement, trait ratability, and the "self-based heuristic." Journal of Research in Personality 34: 208-224.
Reis, H. (2008). Reinvigorating the concept of situation in social psychology. Personality and Social Psychology Review 12: 311-329.

Roberts, B.W., D. Wood \& A. Caspi (2008). Personality development. In: O.P. John \& R.W. Robins (Eds.), Handbook of Personality: Theory and Research (3rd ed., pp. 375-398). New York, N.Y.: Guilford Press.

Srivastava, S., S. Guglielmo \& J.S. Beer (2010). Perceiving others' personalities: examining the dimensionality, assumed similarity to the self, and stability of perceiver effects. Journal of Personality and Social Psychology 98: 520-534.

Vazire, S. (2006). The Person from the Inside and Outside. Unpublished doctoral dissertation, University of Texas at Austin.

Vazire, S. (2010). Who knows what about a person? The Self-Other Knowledge Asymmetry (SOKA) model. Journal of Personality and Social Psychology 98: 281-300.

Walton, K. E., \& B.W. Roberts (2004). On the relationship between substance use and personality traits: Abstainers are not maladjusted. Journal of Research in Personality 38: 515-535.

Widiger, T., A. Frances, M. Harris, L. Jacobsberg, M. Fyer \& D. Manning (1991). Comorbidity among Axis II disorders. In: J. M. Oldman (Ed.), Personality Disorders: New Perspectives on Diagnostic Validity (pp. 165-194). Washington, D.C.: American Psychiatric Press.

Winquist, L., C. Mohr \& D. Kenny (1998). The female positivity effect in the perception of others. Journal of Research in Personality 32: 370-388.

Wonderlic, E. F. (1983). Wonderlic Personnel Test Manual. Northfield, Ill.: Wonderlic \& Associates.

Wood, D., C. Nye \& G. Saucier (2009). Derivation and Measurement of a Representative Set of Person-Descriptive Adjective Markers from the English Lexicon. Unpublished manuscript, Wake Forest University, Winston-Salem, N.C. 